\title{
The Thermodynamic Dissociation Constants of Azathioprine by the Nonlinear Regression and Factor Analysis of Multiwavelength Spectrophotometric pH-Titration Data
}

\author{
Milan Meloun $^{1^{*}, Z}$ Zuzana Ferenčíková $^{1}$, Aleš Vrána ${ }^{2}$ \\ ${ }^{1}$ Department of Analytical Chemistry, University of Pardubice, Pardubice, Czech Republic \\ ${ }^{2}$ Teva Czech Industries, s.r.o., Opava, Czech Republic \\ E-mail:milan.meloun@upce.cz \\ Received January 10, 2009; revised February 21, 2009; accepted February 23, 2009
}

\begin{abstract}
The mixed dissociation constant of azathioprine - chemically 6-(3-methyl-5-nitroimidazol-4-yl)sulfanyl-7Hpurine at various ionic strengths $I$ of range $0.01-0.2$, and at temperatures of $25^{\circ} \mathrm{C}$ and $37^{\circ} \mathrm{C}$, was determined with the use of two different multiwavelength and multivariate treatments of spectral data, SPECFIT32 and SQUAD(84) nonlinear regression analyses and INDICES factor analysis according to a general rule. First, the number of components is determined, and then the spectral responses and concentrations of the components are calculated. Concurrently, the experimental determination of the thermodynamic dissociation constant $\mathrm{p} K_{a}^{\mathrm{T}}$ was in agreement with its computational prediction of the PALLAS programme based on knowledge of the chemical structures of the drug. The factor analysis in the INDICES programme predicts the correct number of two light-absorbing species $\mathrm{L}^{-}$and HL. The thermodynamic dissociation constant $\mathrm{p} K_{a}^{\mathrm{T}}$ of azathioprine was estimated by nonlinear regression of $\left\{\mathrm{p} K_{a}, I\right\}$ data, $\mathrm{p} K_{a}^{\mathrm{T}}=8.07(1)$ at $25^{\circ} \mathrm{C}$ and $7.84(1)$ at $37^{\circ} \mathrm{C}$, where the figure in brackets is the standard deviation in last significant digits. The reliability of the dissociation constants of azathioprine was proven with goodness-of-fit tests of the multiwavelength spectrophotometric $\mathrm{pH}$-titration data.
\end{abstract}

Keywords: Spectrophotometric Titration, Dissociation Constant, Azathioprine, SPECFIT, SQUAD, INDICES, PALLAS

\section{Introduction}

Azathioprine [1], an immunosuppressant, is a drug that is used to suppress the immune system. It is used to treat patients who have undergone kidney transplantation and for diseases in which activity of the immune system is important (psoriasis, severe cutaneous lupus erythematosus, rheumatoid arthritis, severe atopic dermatitis (eczema), cutaneous vasculitis etc.). Azathioprine is a prodrug (a precursor of a drug) which is converted in the body to its active form called mercaptopurine (Purinethol). The exact mechanism of action of azathioprine is not known.

Like other immunosuppressants, it suppresses the proliferation of $\mathrm{T}$ and B lymphocytes, types of white blood cells that are part of the immune system and defend the body against both infectious diseases and foreign materials. For example, in the case of organ transplantation, immunosuppressants prevent the body from immunologically rejecting the new organ. In the case of autoimmune diseases (diseases caused by an abnormal immune reaction against the body's own tissues) such as rheumatoid arthritis, suppressing the immune system reduces the inflammation that accompanies immune reactions and slows damage to the joints caused by the inflammation.

Azathioprine is a pale yellow, odourless powder. It is insoluble in water, soluble in dilute solutions of alkali hydroxides, sparingly soluble in dilute mineral acids and very slightly soluble in alcohol and in chloroform. The sodium salt of azathioprine is sufficiently soluble to make a $10 \mathrm{mg} / \mathrm{mL}$ water solution which is stable for 24 
hours at $59^{\circ} \mathrm{F}$ to $77^{\circ} \mathrm{F}\left(15^{\circ} \mathrm{C}\right.$ to $\left.25^{\circ} \mathrm{C}\right)$. Azathioprine is stable in a solution with neutral or acid $\mathrm{pH}$ but hydrolysis to mercaptopurine occurs with excessive sodium hydroxide $(0.1 \mathrm{M})$, especially on warming [1].

Purine and some of its derivatives (6-mercaptopurine, 6-hydroxypurine (hypoxanthine)) have been studied since the 1950s for their formation of complexes with metal ions and inhibition of purine/oxidizing enzymes [2-6]. The studies further continued in the 70s and 80s [5-7] suggesting that the formation of complexes between 6-mercaptopurine and metal ions, namely $\mathrm{Cu}^{2+}$ and $\mathrm{Ni}^{2+}$, could protect as well as reverse the inhibition of xanthine oxidase [7], adenosine deaminase [5]. The complex formation with metal ions can, together with the transport of these drugs via cell membranes and direct interaction with DNA, serve as major predictors impacting the effect of individual compound on cell proliferation. Whereas the cell membrane penetration is to the maximum extent affected by the lipophilicity of the drug and its molecular weight. The formation of complexes with metal ions is affected by the actual $\mathrm{pH}$ of the specific body fluid [8].

In previous work [9-26], the authors had shown that the potentiometric and spectrophotometric methods in combination with suitable chemometric tools can be used to determine of dissociation constants $\mathrm{p} K_{\mathrm{a}}$. Spectrophotometry is a convenient method for $\mathrm{p} K_{\mathrm{a}}$ determination is possible in very diluted aqueous solutions (about $10^{-5}$ to $10^{-6} \mathrm{M}$ ) even for barely soluble drugs, provided that the compound possesses $\mathrm{pH}$-dependent light absorption due to the presence of a chromophore in proximity to the ionisation centre [18-20,27-40]. The most relevant algorithms are SQUAD [28-33] and SPECFIT [36-39,41].

In this study, we have tried to complete the information on the dissociation constants for azathioprine. As the physiological $\mathrm{pH}$ range of different body fluids in mammals ranges from 1.5 to 8 (Table 1), we tried to mea-<smiles>Cn1cnc([N+](=O)[O-])c1Sc1ncnc2nc[nH]c12</smiles>

Azathioprine, chemically 6-(3-methyl-5-nitroimidazol-4-yl) sulfanyl-7H-purine.

Table 1. Physiological $\mathrm{pH}$ range in body fluids for mammals [1-8,42].

\begin{tabular}{ll}
\hline Blood plasma & 7.4 \\
\hline Cell lysosomes & $<5$ \\
Pancreatic juice & $1.5-3$ \\
Urine & $5-8$ \\
Cell cytosol (liver cells) & 6.9 \\
Gastric juice & $1.5-3$ \\
Saliva & $6.4-7$ \\
\hline
\end{tabular}

sure the dissociation constant of this poorly soluble drug in order to provide more detailed insight into its dissociation/protonation behaviour. Concurrently, the experimental determination of dissociation constants was combined with their computational prediction based on the knowledge of chemical structures [43].

\section{Theoretical}

\subsection{Procedure for the Determination of the Mixed Protonation/Dissociation Constants}

The overall protonation constant of the protonated species, $\beta_{r}$, can then be expressed as

$$
\beta_{r}=\left[\mathrm{LH}_{r}\right] /\left([\mathrm{L}][\mathrm{H}]^{r}\right)=c /\left(l h^{r}\right)
$$

where the free concentration $[\mathrm{L}]=l,[\mathrm{H}]=h$ and $\left[\mathrm{LH}_{r}\right]=$ $c$. For dissociation reactions conducted at constant ionic strength the so-called mixed dissociation constants are defined as

$$
K_{a, j}=\frac{\left[\mathrm{H}_{j-1} \mathrm{~L}\right] a_{\mathrm{H}^{+}}}{\left[\mathrm{H}_{j} \mathrm{~L}\right]}
$$

As each aqueous species is characterized by its own spectrum, for UV/VIS experiments and the $i$ th solution measured at the $j$ th wavelength the Lambert-Beer law relates the absorbance, $A_{i, j}$, being defined as

$$
A_{i, j}=\sum_{n=1}^{n_{c}} \varepsilon_{j, n} c_{n}=\sum_{n=1}^{p}\left(\varepsilon_{r, j} b_{r} l h^{r}\right)_{n}
$$

where $\varepsilon_{r, j}$ is the molar absorptivity of the $\mathrm{LH}_{r}$ species with the stoichiometric coefficient $r$ measured at the $j$ th wavelength. The absorbance $A_{i, j}$ is an element of the absorbance matrix $A$ of size $\left(n_{s} \mathrm{H} n_{w}\right)$ being measured for $n_{s}$ solutions with known total concentrations of $n_{\mathrm{z}}=2$ basic components, $c_{\mathrm{L}}$ and $c_{\mathrm{H}}$, at $n_{w}$ wavelengths. Calculations related to the determination of protonation constants may be performed by the regression analysis of spectra using versions of the SQUAD(84) programme family [28-33] and SPECFIT/32 [36-39,41] with methodology have been described previously $[21,25,26]$.

\subsection{Determination of the Thermodynamic Protonation/Dissociation Constant}

Let us consider the dependence of the mixed dissociation constant $K_{\mathrm{a}}=a_{\mathrm{H}^{+}}\left[\mathrm{L}^{\mathrm{z}-1}\right] /\left[\mathrm{HL}^{\mathrm{Z}}\right]$ on an ionic strength, when both ions $\mathrm{HL}^{\mathrm{z}}$ and $\mathrm{L}^{\mathrm{z}-1}$ have roughly the same ion-size parameter $a$ in the dissociation equilibrium $\mathrm{HL}^{\mathrm{z}} \rightleftarrows \mathrm{L}^{\mathrm{z}-1}+$ $\mathrm{H}^{+}$with the thermodynamic dissociation constant $K_{\mathrm{a}}^{\mathrm{T}}=$ $a_{\mathrm{H}+} \cdot a_{\mathrm{L}}-/ a_{\mathrm{HL}}$. For low values of an ionic strength this dependence is expressed by the shortened Debye-Hückel equation

$$
\mathrm{p} K_{\mathrm{a}}=\mathrm{p} K_{\mathrm{a}}^{\mathrm{T}}-\frac{A(1-2 \mathrm{z}) \sqrt{I}}{1+B a \sqrt{I}}
$$


where $A=0.5112 \mathrm{~mol}^{-1 / 2} \cdot \mathrm{L}^{1 / 2} \cdot \mathrm{K}^{3 / 2}$ and $B=0.3291 \mathrm{~mol}^{-1 / 2}$. $\mathrm{m}^{-1} \cdot \mathrm{L}^{1 / 2} \cdot \mathrm{K}^{1 / 2} \cdot 10^{10}$ for aqueous solutions at $25^{\circ} \mathrm{C}$. The mixed dissociation constant $\mathrm{p} K_{\mathrm{a}}$ represents a dependent variable while the ionic strength $I$ stands for the independent variable. The unknown parameters $\boldsymbol{b}=\left\{\mathrm{p} K_{a}^{\mathrm{T}}, \mathrm{a}\right\}$ are to be estimated by a minimization of the sum of the squared residuals $[44,45]$

$$
\begin{aligned}
& U(\boldsymbol{b})=\sum_{i=1}^{n} w_{i}\left[\mathrm{p} K_{\mathrm{a}, \exp , i}-\mathrm{p} K_{\mathrm{a}, \mathrm{cal}, i}\right]^{2} \\
& =\sum_{i=1}^{n} w_{i}\left[\mathrm{p} K_{\mathrm{a}, \exp , i}-f\left(I ; \mathrm{p} K_{\mathrm{a}}^{\mathrm{T}}, a\right)\right]^{2}=\text { minimum }
\end{aligned}
$$

The nonlinear estimation problem is simply a problem of optimization in the parameter space, in which the $\mathrm{p} K_{\mathrm{a}}$ and $I$ are known and given values while the parameters $\mathrm{p} K_{\mathrm{a}}^{\mathrm{T}}$ and $a$ are unknown variables to be estimated [10, 21-26,29,44,45].

\subsection{Reliability of the Estimated Dissociation Constants}

The adequacy of a proposed regression model with experimental data and the reliability of parameter estimates $\mathrm{p} K_{\mathrm{a}, \mathrm{i}}$ found, being denoted for the sake of simplicity as $b_{j}$, and $\varepsilon_{i j}, j=1, \ldots, m$, may be examined by the goodness-of-fit test, a previous tutorial $[21,47]$.

\subsection{Determination of the Number of Light-Absorbing Species}

A qualitative interpretation of the spectra aims to evaluate of the quality of the dataset and remove spurious data, and to estimate the minimum number of factors, i.e. contributing aqueous species, which are necessary to describe the experimental data. The INDICES [47] determine the number of dominant species present in the equilibrium mixture. The various indicator function $P C(k)$ techniques in INDICES programme developed to deduce the exact size of the true component space can be classified into two general categories and were described in detail previously [9,13]: 1) precise methods based upon a knowledge of the experimental error of the absorbance data, $s_{\text {inst }}(A)$, and 2) approximate methods requiring no knowledge of the experimental error. In general, most precise and approximate methods are based on the procedure on finding the point where the slope of the indicator function $P C(k)=f(k)$ changes.

1) Precise indices: Determination of a number of light-absorbing components in mixture is based on a comparison of an actual index of method used with the experimental error of instrument used, $s_{\text {inst }}(A),[34,47]$ :

a) Kankare's residual standard deviation, $s_{k}(A)$. The $s_{k}(A)$ values for different numbers of components $k$ are plotted against an index $k, s_{k}(A)=f(k)$, and the number of significant components is an integer $n_{c}=k$ for which $s_{k}(A)$ is close to the instrumental error of absorbance $s_{\text {inst }}(A),[9,34]$.

b) Residual standard deviation, $R S D(k)$, is used analogously as in previous method $s_{k}(A)$.

c) Root mean square error, RMS: analogically as in previous method.

d) Average error criterion, $A E(k)$, is used analogously as in the preceding method $s_{k}(A)$.

e) Bartlett $\chi^{2}$ criterion, $\chi^{2}(k)$ is used when the true number of significant components corresponds to the first $k$ value for which $\chi^{2}(k)$ is less than critical $\chi^{2}(k)_{\text {expected }}$ $=(n-k)(m-k)$.

f) Standard deviation of eigenvalues $s(g)$.

g) Eigenvalues: the first $k$ eigenvalues being called a set of primary eigenvalues contain contribution from the real components and should be considerably larger than those containing only noise.

2) Approximate methods: Most of the techniques presented here are empirical functions.

a) Exner function $\psi(k)$ : The $\psi(k)=(k)$ function can vary from zero to infinity, with the best fit approaching zero.

b) Scree test, $R P V(k)$ : When the residual percent variance is plotted against the number of $k$ PC dimensions used in the data reproduction, $R P V(k)=f(k)$, the curve should drop rapidly and level off at some point.

c) Imbedded error function, $\operatorname{IE}(k)$ : The imbedded error function $I E(\mathrm{k})$ is an empirical function developed to identify those $k$ latent variables which contain error without relying upon an estimate of the error associated with the absorbance data matrix.

d) Factor indicator function, $\operatorname{IND}(k)$ : The factor indicator function $\operatorname{IND}(k)$ is an empirical function which reaches a minimum when the correct number of latent variables or $k \mathrm{PC}$ dimensions is employed in the data reproduction.

3) Ratio of eigenvalues calculated by smoothed PCA and those by ordinary PCA, RESO $(k)$ :

The index $R E S O_{i}^{k}$ or the ratios between $\lambda_{k, i}^{s} / \lambda_{i}^{0}$ for different $k$ and plot $\log \left(\operatorname{RESO}_{i}^{k}\right)$ versus component number is calculated. The number of components by examining the $\log \left(\operatorname{RESO}_{i}^{k}\right)$ versus component number plots is estimated. The number of $\log \left(\operatorname{RESO}_{i}^{k}\right)$ which are very close to each other and do not change substantially with the variation of $k$ in comparison with the remaining $\log \left(\operatorname{RESO}_{i}^{k}\right)$ is located. This is the number of components existing in the examined mixture.

\subsection{Signal-to-Noise Ratio $S E R$}

The level of "experimental noise" should be used in the experiment as a critical factor. Therefore, it is necessary to have a consistent definition of the signal-to-noise ratio 
$S N R$ so that the impact of this parameter can be critically assessed. Traditional approaches to $S N R$ are typically based on the ratio of the maximum signal to maximum noise value. As an alternative, the concept of instrumental error was again employed and the signal-to-error ratio $S E R$ is defined where for an error the instrumental standard deviation of absorbance, $s_{\text {inst }}(A)$ is used. The plot of small absorbance changes in the spectrum of the drug studied means that the value of the absorbance difference for the $j$ th-wavelength of the $i$ th-spectrum $\Delta_{i j}=$ $A_{i j}-A_{i, \text { acid }}$ is divided by the instrumental standard deviation $s_{\text {inst }}(A)$, and the resulting ratios $S E R=\Delta / s_{\text {inst }}(A)$ are plotted in dependence of wavelength $\lambda$ for all absorbance matrix elements, where $A_{i, a c i d}$ is the initial spectrum of the acid form of the drug being measured for the starting $\mathrm{pH}$ value of the $\mathrm{pH}$ range studied. This SER ratio is then compared with the limiting $S E R$ value to test if the absorbance changes are significantly larger than the instrumental noise.

The plot of the ratio $e / s_{\text {inst }}(A)$, i.e., the ratio of the residuals divided by the instrumental standard deviation $s_{\text {inst }}(A)$ on wavelength $\lambda$ for all the residual matrix elements for tests if the residuals are of the same or similar magnitude as the instrumental noise.

\section{Experimental}

\subsection{Chemicals and Solutions}

Hydrochlorid acid, $1 \mathrm{M}$, was prepared from conc. $\mathrm{HCl}$ (p. a., Lachema Brno) using redistilled water and standardized against $\mathrm{HgO}$ and $\mathrm{KI}$ with reproducibility of less than $0.20 \%$. Potassium hydroxide, $1 \mathrm{M}$, was prepared from pellets (p. a., Aldrich Chemical Company) with carbondioxidefree redistilled water and standardized against standardized $\mathrm{HCl}$ with a reproducibility of $0.1 \%$. The preperation of other solutions from analytical reagent-grade chemicals has been described previously [21-26]. Azathioprine $5 \times 10^{-5} \mathrm{M}$, was prepared from solid samples (Teva Czech Industries, s.r.o., Opava) using redistilled water. High purity of the substances (over $98 \%$ ) was guaranteed by the supplier.

\subsection{Apparatus and pH-Spectrophotometric Titration Procedure}

The apparatus used and the $\mathrm{pH}$-spectrophotometric titration procedure have been previously described in details $[18-21,25,26]$. The experimental and computation scheme for the determining the protonation constants of the multicomponent system is taken from Meloun et al., page 226 in [18] and the five steps are described in a previous contribution [21]: 1) instrumental error of absorbance measurements, $s_{\text {inst }}(A), 2$ ) experimental design, 3) number of light-absorbing species, 4) choice of computational strategy, 5) diagnostics indicating a correct chemical model: When a minimization process terminates, some diagnostics are examined to determine whether the results should be accepted: the physical meaning of parametric estimates, the physical meaning of the species concentrations, the goodness-of-fit test and the deconvolution of spectra.

\subsection{Software Used}

Computation relating to the determination of dissociation constants were performed by regression analysis of the UV/VIS spectra using the $\operatorname{SQUAD}(84)$ [30] and SPECFIT/32 [41] programmes. Most graphs were plotted using ORIGIN 7.5 [46] and S-Plus [48]. The thermodynamic dissociation constant $\mathrm{p} K_{\mathrm{a}}^{\mathrm{T}}$ was estimated with the MINOPT nonlinear regression programme in the ADSTAT statistical system [49]. A qualitative interpretation of the spectra with the use of the INDICES programme [47] aims to evaluate the quality of the dataset and remove spurious data, and to estimate the minimum number of factors, i.e., contributing aqueous species, which are necessary to describe the experimental data and determine the number of dominant species present in the equilibrium mixture. PALLAS [43] is a programme for making predictions based on the structural formulae of drug compounds. Entering the compound topological structure descriptors graphically, $\mathrm{p} K_{\mathrm{a}}$ values of organic compound are predicted using approximately hundreds of Hammett and Taft equations and quantum chemistry calculus.

\subsection{Supporting Information Available}

Complete experimental and computational procedures, input data specimens and corresponding output in numerical and graphical form for the programmes, INDICES, SQUAD(84) and SPECFIT/32 are available free of charge on line at http://meloun.upce.cz and in the block DOWNLOAD and DATA.

\section{Results and Discussion}

Recently, azathioprine studied in our laboratory exhibits quite small changes in spectra. Other instrumental methods could not be used to determine dissociation constants for limited solubility in water.

The deprotonation azathioprine $\mathrm{LH}$ form indicates one simple equilibrium. $\mathrm{pH}$-spectrophotometric titration enables absorbance-response data (Figure 1(a)) to be obtained for analysis by non-linear regression, and the reliability of parameter estimates ( $\mathrm{p} K$ and $\varepsilon$ ) can be evaluated on the basis of a goodness-of-fit test of the residuals (Figure 1(b)). As the changes in spectra are quite small within deprotonation, however, both of the variously pro- 

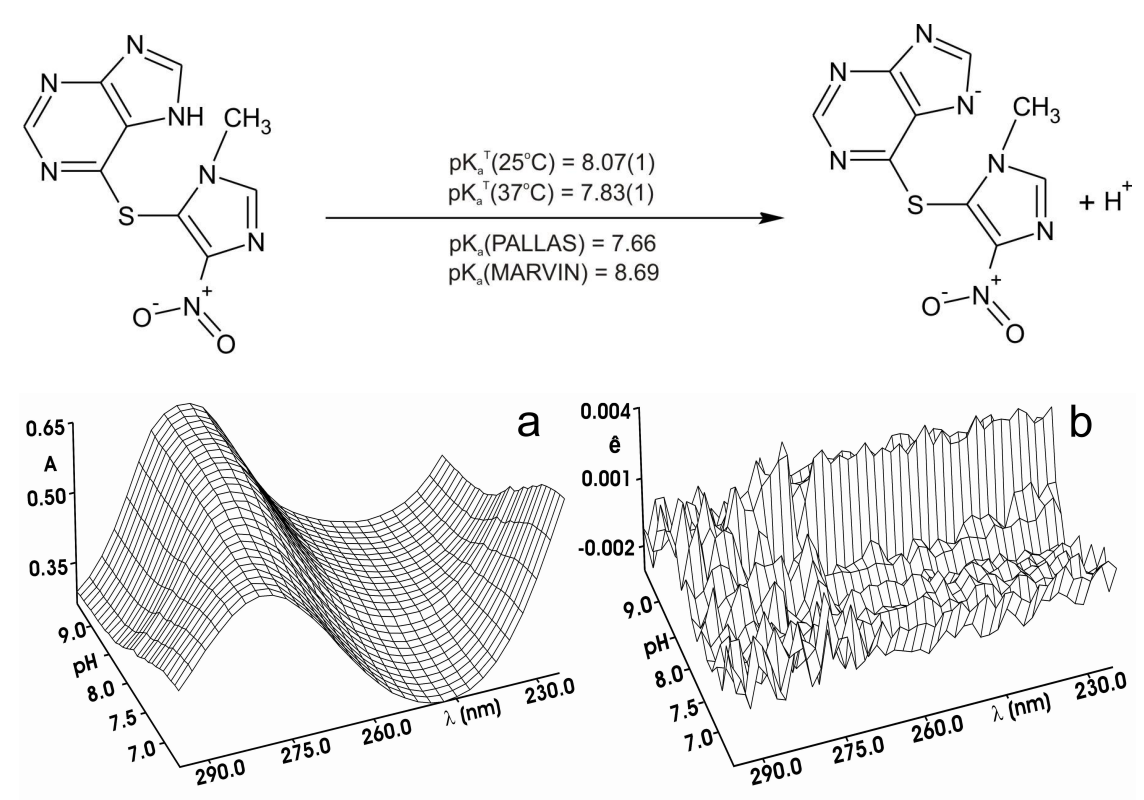

Figure 1. The 3D-absorbance-response-surface representing the measured multiwavelength absorption spectra in dependence on $\mathrm{pH}$ at $25^{\circ} \mathrm{C}$ for (a) azathioprine, (b) the 3D-residuals map after non-linear regression performed with SPECFIT and SQUAD(84), (S-Plus).

tonated species $\mathrm{L}^{-}$and $\mathrm{LH}^{-}$exhibit similar absorption bands. The small shift of a band maximum to higher wavelengths in the spectra set with increasing $\mathrm{pH}$ is shown in Figure 3(a). The adjustment of $\mathrm{pH}$ value from 5.5 to 9 causes the absorbance to change by $18 \mathrm{mAU}$ only, so that the monitoring of both components $\mathrm{L}^{-}$and $\mathrm{LH}$ of the protonation equilibrium is rather difficult. As the changes in spectra are very small, a very precise measurement of absorbance is required for the reliable estimation of the deprotonation equilibrium studied.

In the first step of the regression spectra analysis the number of light-absorbing species $n_{c}$ is estimated by the INDICES algorithm (Figures 2 and 3(b)). The position of the break point on the $s_{k}(A)=f(k)$ curve in the factor analysis scree plot is calculated and gives $k=2$ and so $n_{c}$ $=2$ with corresponding co-ordinate $s_{k}(A)=0.81 \mathrm{mAU}$, and this value also represents the actual instrumental error $s_{\text {inst }}(A)$ of the spectrophotometer used. Due to the large variations in the indicator values, these latter are plotted on a logarithmic scale. All other selected methods of the modified factor analysis in the INDICES algorithm prove the two light-absorbing components $\mathrm{L}^{-}$and LH of the protonation equilibrium. The $A-\mathrm{pH}$ curves at 235, 280, and $295 \mathrm{~nm}$ (Figure 3(c)) also show that a dissociation constant may also be indicated.

The dissociation constant and the two molar absorptivities of azathioprine $\varepsilon_{\mathrm{L}}$ and $\varepsilon_{\mathrm{HL}} \varepsilon_{\mathrm{L}}$ calculated for 29 wavelengths of 30 spectra constitute $(2 \times 29)+1=59$ unknown regression parameters, which are estimated and refined by SQUAD(84) or SPECFIT32 in the first run. The reliability of the parameter estimates may be tested with the use of the following diagnostics:
The first diagnostic value indicates whether all of the parametric estimates $\mathrm{p} K_{\mathrm{a}}$ and $\varepsilon_{\mathrm{L}}$ and $\varepsilon_{\mathrm{HL}}$ have physical meaning and reach realistic values: for azathioprine $\mathrm{p} K_{\mathrm{a}}^{\mathrm{T}}$ $=8.025(s=0.005)$ at $25^{\circ} \mathrm{C}$ while PALLAS(2004) predicts $\mathrm{p} K_{\text {a,pred }}=7.66$. As the standard deviations $s\left(\mathrm{p} K_{\mathrm{a}}\right)$ of parameters $\mathrm{p} K_{\mathrm{a}}, \varepsilon_{\mathrm{L}}$ and $\varepsilon_{\mathrm{HL}}$ are significantly smaller than their parameter estimates, all the variously protonated species are statistically significant at a significance level $\alpha$ $=0.05$. The absolute values of $s\left(\mathrm{p} K_{\mathrm{a}}\right), s(\varepsilon)$ give information about the last $U$-contour of the hyperparaboloid in the neighbourhood of the pit, $U_{\min }[21,25]$. For well-conditioned parameters, the last $U$-contour is a regular ellipsoid, and the standard deviations are reasonably low. High $s$ values may be found with ill-conditioned parameters and a "saucer"-shaped pit. The relationship $s\left(\beta_{\mathrm{j}}\right) \times F_{\sigma}<\beta_{\mathrm{j}}$ should be met where $F_{\sigma}$ is equal to 3 for a $99.9 \%$ statistical probability level and $\beta_{\mathrm{j}}$ stands for $\mathrm{p} K_{\mathrm{a}}$ and $\varepsilon_{\mathrm{L}}$ and $\varepsilon_{\mathrm{HL}}$. The set of standard deviations of $\varepsilon_{\mathrm{L}}$ and $\varepsilon_{\mathrm{HL}}$ for various wavelengths should exhibit a Gaussian distribution; otherwise erroneous estimates of the vector $\boldsymbol{\varepsilon}$ are obtained. Figure 3(e) shows the estimated molar absorptivities of both variously protonated species $\varepsilon_{\mathrm{L}}$ and $\varepsilon_{\mathrm{HL}}$, of the azathioprine on wavelength.

The second diagnostic tests whether the calculated free concentrations of both variously protonated species of azathioprine on the distribution diagram of the relative concentration expressed as a percentage have physical meaning, which proved to be the case (Figure 3(f)). A distribution diagram of relative concentration [in \%] of azathioprine on $\mathrm{pH}$ makes it easier to quickly judge the contributions of the individual species to the total con- 


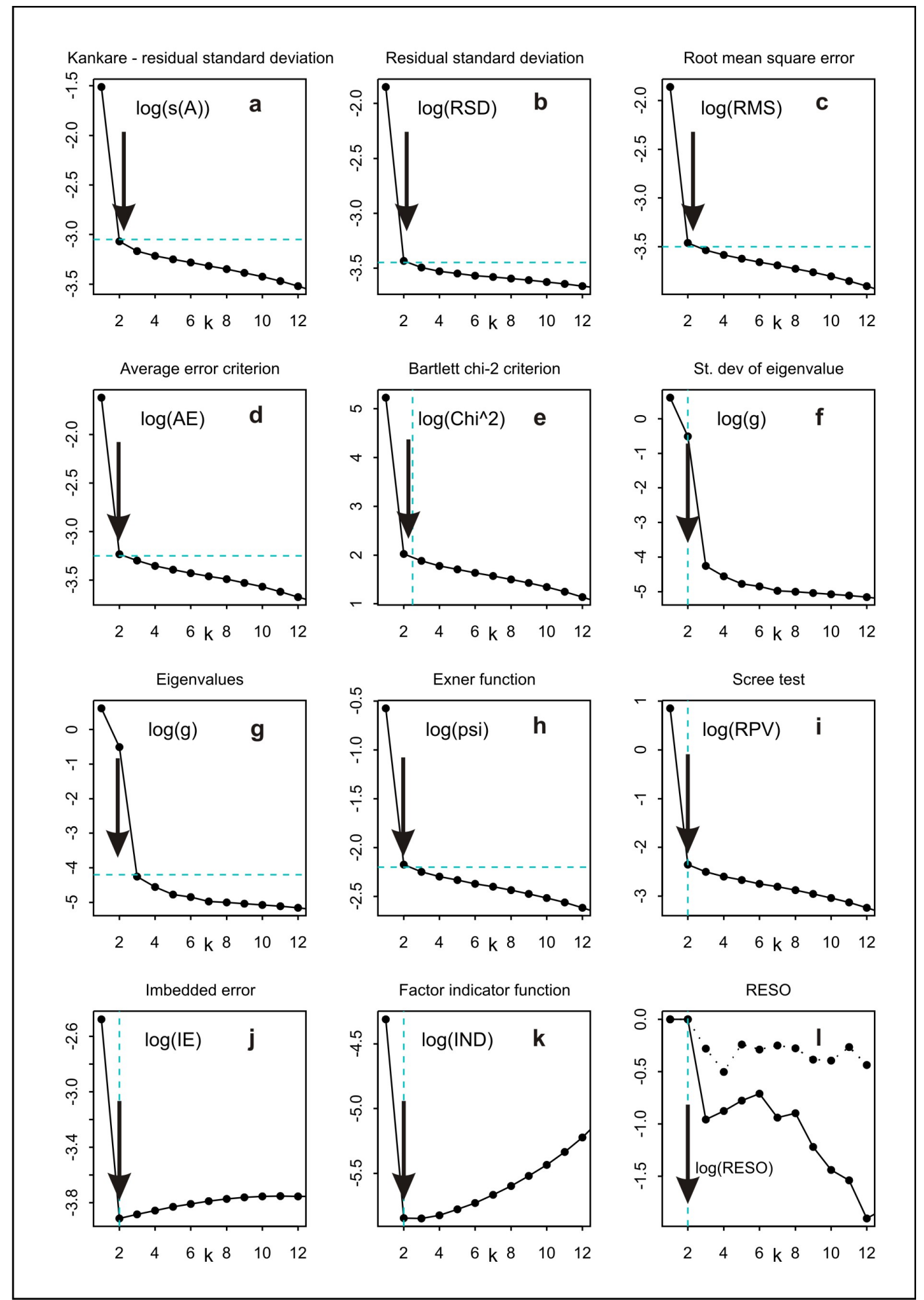

Figure 2. The logarithm dependence of the Cattel's index plot of eigenvalues in the form of 12 indices modifying methods as a function of the number of principal components $k$ for the pH-absorbance matrix: (a) Kankare's residual standard deviation, $s_{k}(A)$, (b) Residual standard deviation, $R S D(k)$, (c) Root mean square error, RMS, (d) Average error criterion, AE(k), (e) Bartlett $\chi^{2}$ criterion, $\chi^{2}(k)$, (f) Standard deviation of eigenvalues $s(g)$, (g) Eigenvalues, (h) Exner function $\psi(k)$, (i) Scree test, RPV(k), (j) Imbedded error function, IE(k), (k) Factor indicator function, IND(k), (l) Ratio of eigenvalues calculated by smoothed PCA and those by ordinary PCA, RESO $(k)$. The arrows indicate that most of methods lead to 2 light-absorbing species in pH-equilibrium mixture. (S-Plus). 

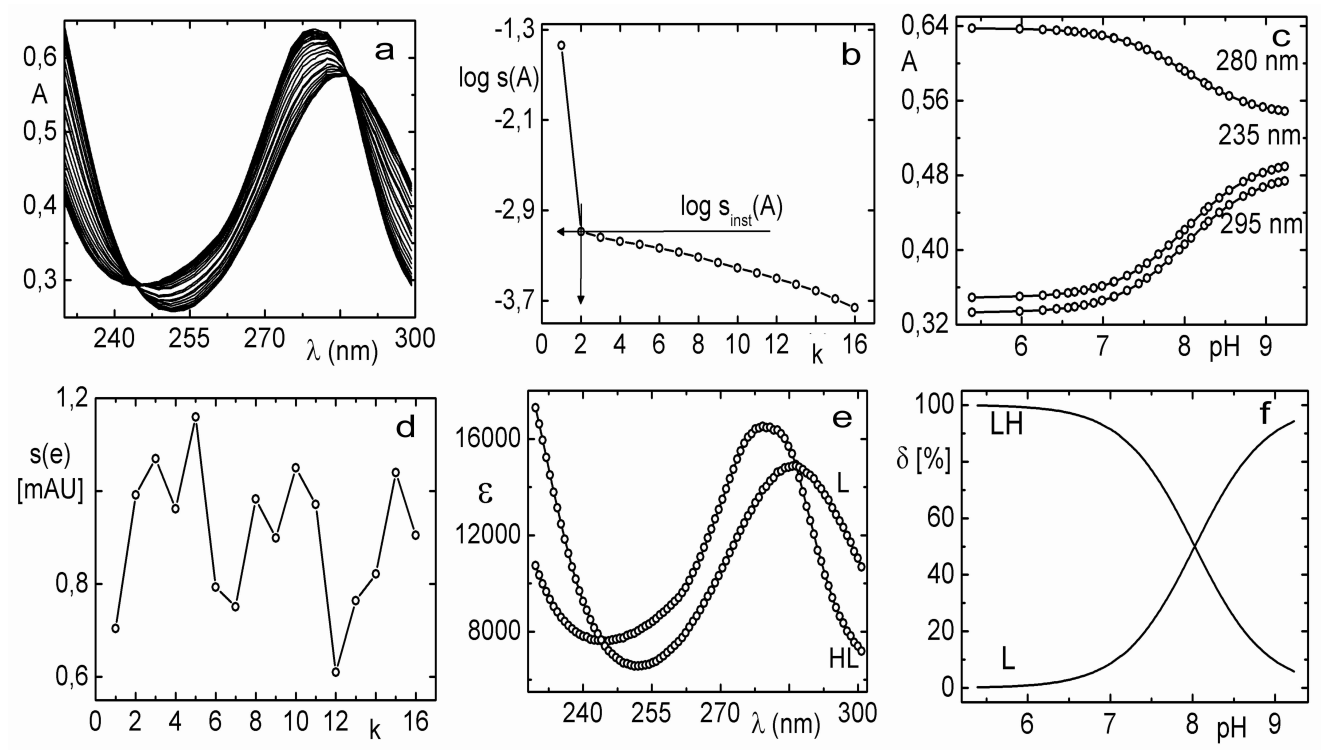

Figure 3. Non-linear regression analysis of the protonation equilibria model and factor analysis of azathioprine: (a) Absorption spectra on $\mathrm{pH}$ at $25^{\circ} \mathrm{C}$; (b) Cattel's scree plot of the Wernimont-Kankare procedure for the determining the number of light-absorbing species in the mixture $k^{*}=2$ leads to $n_{c}=2$ and the actual instrumental error of the spectrophotometer used $s_{\text {inst }}(A)=0.81 \mathrm{mAU}$ (INDICES in S-Plus); (c) the absorbance $v s$. $\mathrm{pH}$ curves for $280 \mathrm{~nm}, 235 \mathrm{~nm}$ and $295 \mathrm{~nm}$ in dependence on $\mathrm{pH}$ at $25^{\circ} \mathrm{C}$; (d) detecting influential outlying spectra with the use of the goodness-of-fit test and the plot of the residual standard deviation $s(e) v s \mathrm{pH}$ for 19 spectra in dependence on $\mathrm{pH}$ at $25^{\circ} \mathrm{C}$; (e) pure spectra profiles of molar absorptivities $v s$. wavelengths for the variously protonated species L, LH; (f) distribution diagram of the relative concentrations of both variously protonated species $\mathrm{L}, \mathrm{LH}$, of azathioprine in dependence on $\mathrm{pH}$ at $25^{\circ} \mathrm{C}$. The charges of species in figures are omitted for the sake of simplicity (SPECFIT, ORIGIN).

centration. Since the molar absorptivities will generally be in the range $10^{3}-10^{5} \mathrm{~L} \cdot \mathrm{mol}^{-1} \cdot \mathrm{cm}^{-1}$, species present at less than $0.1 \%$ relative concentration will affect the absorbance significantly only if their $\varepsilon$ is extremely high. The distribution diagram presents the protonation equilibrium of $\mathrm{LH} / \mathrm{L}^{-}$.

The next diagnostic concerns the goodness-of-fit (Figure 3(d)). The goodness-of-fit achieved is easily seen by examination of the differences between the experimental and calculated values of absorbance, $e_{i}=$ $A_{\text {exp }, i, j}-A_{\text {calc }, i, j}$. Examination of the spectra and of the graph of the predicted absorbance response-surface through all the experimental points should reveal whether the results calculated are consistent and whether any gross experimental errors have been made in the measurement of the spectra. One of the most important statistics calculated is the standard deviation of absorbance, $s(A)$, calculated from a set of refined parameters at the termination of the minimization process. It is usually compared with the standard deviation of absorbance calculated by the INDICES programme [44,45], $s_{k}(A)$, and if $s(A) \leq s_{k}(A)$, or $s(A) \leq s_{\text {inst }}(A)$, the instrumental error of the spectrophotometer used, the fit is considered to be statistically acceptable. This proves that the $s_{2}(A)=0.81$ $\mathrm{mAU}$ is close to the standard deviation of absorbance when the minimization process terminates, $s(A)=0.62$ $\mathrm{mAU}$. Although this statistical analysis of the residuals
[21,25] gives the most rigorous test of the degree-of-fit, realistic empirical limits must be used. The statistical measures of all residuals $e$ prove that the minimum of the elliptic hyperparaboloid $U$ is reached: the residual standard deviation $s(e)$ always has sufficiently low values. The criteria of resolution used for the hypotheses were: 1) a failure of the minimization process in divergency or cyclisation; 2) an examination of the physical meaning of the estimated parameters to ensure that they were both realistic and positive; and 3) the residuals should be randomly distributed about the predicted regression spectrum, systematic departures from randomness being taken to indicate that either the chemical model or the parameter estimates were unsatisfactory.

To express small changes of absorbance in the spectral set, the absorbance differences for the $j$ th wavelength of the $i$ th spectrum $\Delta_{i}=A_{i j}-A_{i, a c i d}$ were calculated so that from the absorbance value of the spectrum measured at the actual $\mathrm{pH}$ the absorbance value of the acidic form of azathioprine was subtracted. The absorbance difference $\Delta_{i}$ was then divided by the actual instrumental standard deviation $s_{\text {inst }}(A)$ of the spectrophotometer used, and the resulting value represents the signal-to-error value $S E R$. Figure 4(a) is a graph of the $S E R$ on wavelength in the measured range for azathioprine. When the SER is larger than 10 , a factor analysis is sufficiently able to predict the correct number of light-absorbing components in the 
equilibrium mixture. To prove that non-linear regression also can analyze such data of small absorbance changes the residuals set was compared with the instrumental noise $s_{\text {inst }}(A)$. If the ratio $e / \mathrm{s}_{\text {inst }}(A)$ is of similar magnitude i.e. nearly equal to one, it means that sufficient curve fitting was achieved by the non-linear regression of the spectra set and that the minimization process found the minimum of the residual-square-sum function $U_{\text {min }}$. Fig. $4 \mathrm{~b}$ shows a comparison of the ratio $e / \mathrm{s}_{\text {inst }}(A)$ on wavelength for the azathioprine measured. From the figure it is obvious that most of the residuals are of the same magnitude as the instrumental noise and so proves sufficient reliability of the regression process performed.

Resolution of each experimental spectrum into spectra of the individual species proves whether the experimen- tal design is efficient, Figure 5. If, for a particular $\mathrm{pH}$ range, the spectrum of azathioprine consists of just a single component, further spectra for that range would be redundant, although they could improve the precision. In $\mathrm{pH}$ ranges where more components contribute significantly to the spectrum, several spectra should be measured. The spectra deconvolution on Figure 5, emerges as quite a useful tool in the proposal of a strategy for efficient experimentation. Such a spectrum provides sufficient information for a regression analysis which monitors at least two species in equilibrium where none of them is a minor species. The minor species has a relative concentration in a distribution diagram of less than $5 \%$ of the total concentration of the basic component $c_{\mathrm{L}}$. When, on the other hand, only one species prevails in solution,
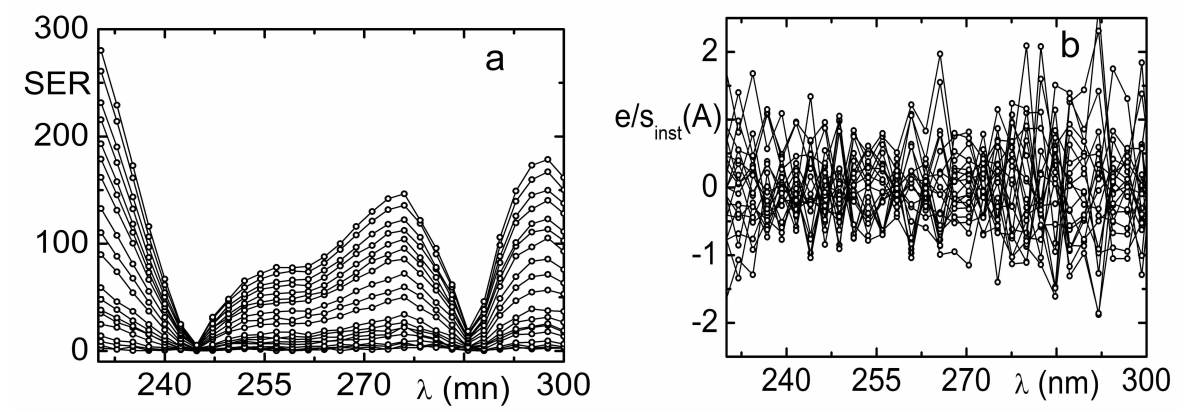

Figure 4. (a) The plot of small absorbance changes in the spectrum of the azathioprine means that the value of the absorbance difference for the $j$ th-wavelength of the $i$ th-spectrum $\Delta_{i j}=A_{i j}-A_{i, \text { acid }}$ is divided by the instrumental standard deviation $s_{\text {inst }}(A)$, and the resulting ratios $S E R=\Delta / s_{\text {inst }}(A)$ are plotted in dependence of wavelength $\lambda$ for all absorbance matrix elements, where $A_{i, a c i d}$ is the limiting spectrum of the acid form of the azathioprine measured. This ratio is compared with the limiting $S E R$ value for the azathioprine to test if the absorbance changes are significantly larger than the instrumental noise; (b) The plot of the ratio $e / s_{\text {inst }}(A)$, i.e., the ratio of the residuals divided by the instrumental standard deviation $s_{\text {inst }}(A)$ in dependence on wavelength $\lambda$ for all the residual matrix elements for azathioprine proves that the residuals are of the nearly same magnitude as the instrumental noise.
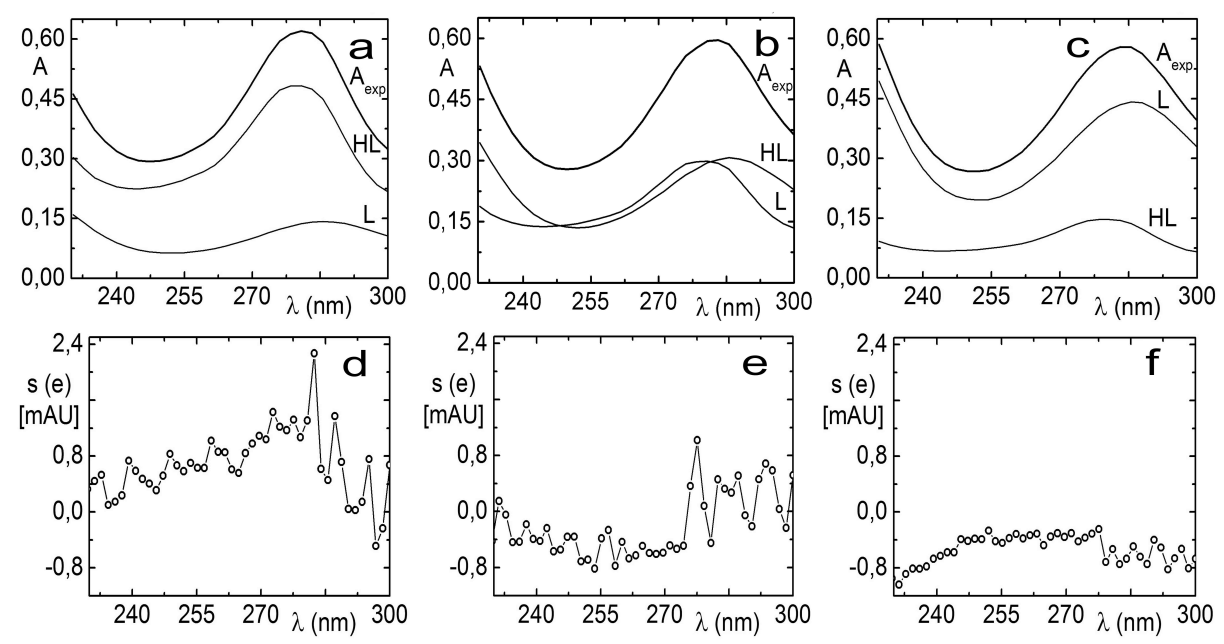

Figure 5. Deconvolution of the experimental absorption spectrum of the azathioprine for 39 wavelengths into spectra of the individual variously protonated species $L$ and $L H$, in solution $(a, b, c)$ and the statistical analysis of the residuals (d, e, $f$ ) of each particular absorption spectrum for a selected value of pH equal to: (a) 7.54, (b) 8.80 and (c) 8.55 . The charges of species are omitted for the sake of simplicity (SQUAD, ORIGIN). 
Table 2. Dependence of the estimated mixed dissociation constants $\mathrm{p} K_{\mathrm{a}}$ of azathioprine on ionic strength using regression analysis of $\mathrm{pH}$-spectrophotometric data with SPECFIT and SQUAD at $25^{\circ} \mathrm{C}$ and at $37^{\circ} \mathrm{C}$. The standard deviations of the $\mathrm{p} K_{\mathrm{a}}$ in the last valid digits are in brackets.

\begin{tabular}{|c|c|c|c|c|c|c|c|}
\hline \multicolumn{8}{|c|}{ Estimated dissociation constants $\mathrm{p} K_{\mathrm{a}}$ at $25^{\circ} \mathrm{C}$} \\
\hline Ionic strength & & 0.0023 & 0.0224 & 0.0532 & 0.1131 & 0.1661 & 0.2185 \\
\hline \multirow{2}{*}{ SPECFIT } & $\mathrm{pK}_{\mathrm{a}}$ & $8.025(5)$ & $8.016(6)$ & $7.998(6)$ & $7.967(7)$ & $7.960(7)$ & $7.949(8)$ \\
\hline & $s(A)[\mathrm{mAU}]$ & 0.62 & 0.77 & 0.72 & 0.89 & 0.64 & 0.61 \\
\hline \multirow{2}{*}{ SQUAD } & $\mathrm{pK}_{\mathrm{a}}$ & $8.025(2)$ & $8.016(2)$ & $7.997(2)$ & $7.967(2)$ & $7.960(3)$ & $7.949(3)$ \\
\hline & $s(A)[\mathrm{mAU}]$ & 0.86 & 0.97 & 0.92 & 1.43 & 0.96 & 1.01 \\
\hline \multicolumn{8}{|c|}{ Estimated dissociation constants $\mathrm{p} K_{\mathrm{a}}$ at $37^{\circ} \mathrm{C}$} \\
\hline Ionic strength & & 0.0018 & 0.0223 & 0.0532 & 0.1132 & 0.1661 & 0.2175 \\
\hline \multirow{2}{*}{ SPECFIT } & $\mathrm{pK}_{\mathrm{a}}$ & 7.794(8) & $7.755(13)$ & $7.749(11)$ & 7.737(8) & $7.733(7)$ & $7.727(10)$ \\
\hline & $s(A)[\mathrm{mAU}]$ & 0.74 & 1.02 & 1.05 & 0.68 & 0.66 & 0.84 \\
\hline \multirow{2}{*}{ SQUAD } & $\mathrm{pK}_{\mathrm{a}}$ & $7.796(3)$ & $7.756(4)$ & $7.750(3)$ & $7.736(2)$ & $7.733(2)$ & $7.727(3)$ \\
\hline & $s(A)[\mathrm{mAU}]$ & 1.06 & 1.32 & 1.40 & 0.95 & 0.95 & 1.08 \\
\hline
\end{tabular}

Table 3. Thermodynamic dissociation constants $p K_{a}$ for azathioprine at $25^{\circ} \mathrm{C}$ and $37^{\circ} \mathrm{C}$. The standard deviations in the last valid digits are in brackets.

\begin{tabular}{cccc}
\hline & \multicolumn{2}{c}{ Estimated with SPECFIT } & Predicted with \\
PALLAS & Value at $37^{\circ} \mathrm{C}$ & 7.66 \\
$\mathrm{p} K_{\mathrm{a}}^{\mathrm{T}}$ & Value at $25^{\circ} \mathrm{C}$ & $7.835(2)$ & \\
\hline
\end{tabular}
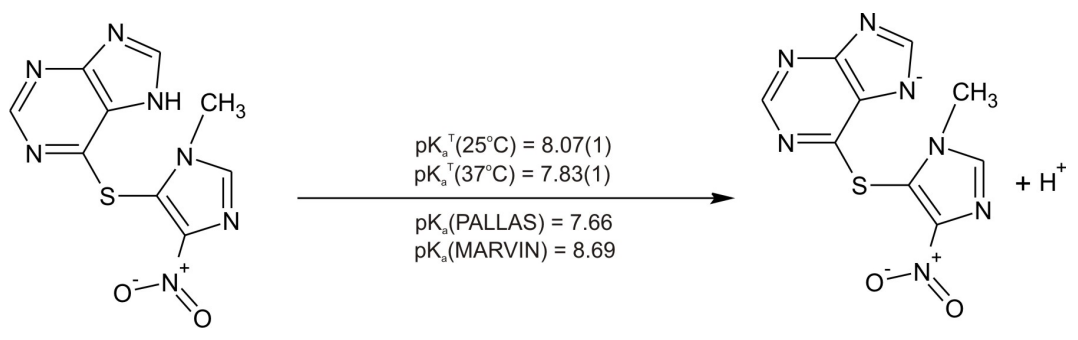

Dissociation of azathioprine

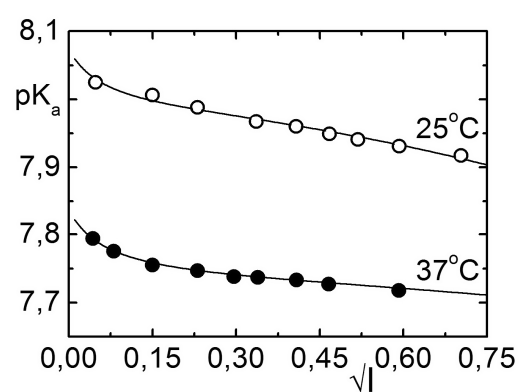

Figure 6. Dependence of the mixed dissociation constant $\mathrm{p} K_{\mathrm{a}}$ of the azathioprine on the square root of ionic strength, which lead to the parameter estimates of $\mathrm{pK}_{\mathrm{a}}^{\mathrm{T}}=\mathbf{8 . 0 7 3}(7)$ at $25^{\circ} \mathrm{C}$ and $\mathrm{p} K_{\mathrm{a}}^{\mathrm{T}}=7.835(2) 37^{\circ} \mathrm{C}$.

the spectrum yields quite poor information for a regression analysis and the parameter estimate is rather unsure and definitely not reliable enough.
Applying a Debye-Hückel equation to the data in Table 2 according to the regression criterion (6), the unknown parameter $\mathrm{p} K_{\mathrm{a}}^{\mathrm{T}}$ has been estimated. Table 3 brings point estimates of the thermodynamic dissociation constants of azathioprine studied at two temperatures. Because of the narrow range of ionic strength the ion-size parameter $\stackrel{a}{a}$ could not be estimated here.

\section{Conclusions}

When drugs are poorly soluble, $\mathrm{pH}$-spectrophotometric titration may be used with the non-linear regression of the absorbance-response-surface data instead of performing a potentiometric determination of the dissociation constants. The reliability of the dissociation constants of the drug azathioprine studied may be proven with goodness-of-fit tests of the absorption spectra measured at various $\mathrm{pH}$. The thermodynamic dissociation 
constant $\mathrm{p} K_{\mathrm{a}}^{\mathrm{T}}$ for azathioprine was estimated by non-linear regression of $\left\{\mathrm{p} K_{\mathrm{a}}, I\right\}$ data at $25^{\circ} \mathrm{C} \mathrm{p} K_{\mathrm{a}}^{\mathrm{T}}=$ $8.073(6)$ at $37^{\circ} \mathrm{C} \mathrm{p} K_{\mathrm{a}}^{\mathrm{T}}=7.835(2)$ where in brackets is the standard deviation is in the last significant digits.

Goodness-of-fit tests for the various regression diagnostics enabled the reliability of the parameter estimates to be determined. Most indices always predict the correct number of components when the signal-to-error ratio SER is higher than 10 . The Wernimont-Kankare procedure in INDICES performs a reliable determination of the instrumental standard deviation of spectrophotometer used $s_{\text {inst }}(A)$, correctly predicts the number of light-absorbing components present $n_{c}$ and can also solve an ill-defined problem with severe collinearity in the spectra or very small changes in spectra.

\section{Acknowledgments}

The financial support of the Grant Agency IGA MZ ČR (Grant No NS9831-4/2008) and of the Czech Ministry of Education (Grant No MSM0021627502) is gratefully acknowledged.

\section{References}

[1] “Azathioprine," Encyclopedia Britannica, 2009. http://www. britannica.com/EBchecked/topic/46740/azathioprine

[2] G. E. Cheney, H. Freiser and Q. Fernando, "Metal Complexes of Purine and some of its Derivatives," Journal of the American Chemical Society, Vol. 81, No. 11, 1959, pp. 2611-2615.

[3] D. E. Duggan and E. Titus, "6-Chloropurine and 6Chlorouric Acid as Substrates and Inhibitors of PurineOxidizing Enzymes," Journal of Biological Chemistry, Vol. 234, No. 8, 1959, pp. 2100-2104.

[4] J. D. Davidson, "Studies on the Mechanism of Action of 6-Mercaptopurine in Sensitive and Resistant L1210 Leukemia in Vitro," Cancer Research, Vol. 20, No. 2, 1960, pp. 225-232.

[5] U. Kela and R. Vijayvargiya, "Studies on the Mechanism of Action of 6-Mercaptopurine," Biochemistry Journal, Vol. 193, No. 3, 1981, pp. 799-803.

[6] E. Mavioglu, S. Arzik and A. S. Celebi: Potentric Determination of the Stability Constants of $\mathrm{Ni}(\mathrm{II}), \mathrm{Co}(\mathrm{II})$, $\mathrm{Cu}(\mathrm{II})$ and $\mathrm{Zn}$ (II) Complexes of Hypoxanthine at Physiological Conditions. JFS 27 (2004), 1-19

[7] M. J. Robins and G. L. Basom, "Nucleic Acid Related Compounds. 8. Direct Conversion of 2'-Deoxyinosine to 6-Chloropurine 2'-Deoxyriboside and Selected 6-Substitued Deoxynucleosides and their Evaluation as Substrates of Adenosine Deaminase," Canadian Journal of Chemistry, Vol. 51, No. 19, 1973, pp. 3161-3169

[8] O. Bibi, J. Schwartz, Y. Eilam, E. Shohami and Z. I. Cabantchik, "Nucleoside Transport in Mammalian Cell. IV. Organomercurials and Organomercurial-Mercaptonucleo- side Complexes as Probes for Nucleoside Transport Systems in Hamster Cells," Journal of Membrane Biology, Vol. 39, No. 2-3, 1978, pp. 159-183

[9] M. Meloun, J. Čapek, P. Mikšík and R. G. Brereton, "Critical of Methods Predicting the Number of Components in Spectroscopic Data," Analytica Chimica Acta, Vol. 423, No. 1, 2000, pp. 51-68.

[10] M. Meloun and M. Pluhařová, "Thermodynamic Dissociation Constants of Codeine, Ethylmorphine and Homatropine by Regression Analysis of Potentiometric Titration Data, Analytica Chimica Acta, Vol. 416, No. 1, 2000 pp. 55-68.

[11] M. Meloun and P. Černohorský, "Thermodynamic Dissociation Constants of Isocaine, Physostigmine and Pilocarpine by Regression Analysis of Potentiometric Data," Talanta, Vol. 52, No. 5, 2000, pp. 931-945.

[12] M. Meloun, D. Burkoňová, T. Syrový and A. Vrána: The Thermodynamic Dissociation Constants of Silychristin, Silybin, Silydianin and Mycophenolate by the Regression Analysis of Spectrophotometric Data, Analytica Chimica Acta, Vol. 486, No. 1, 2003, pp. 125-141.

[13] M. Meloun, T. Syrový and A. Vrána, "Determination of the Number of Light-Absorbing Species in the Protonation Equilibria of Selected Drugs," Analytica Chimica Acta, Vol. 489, No. 2, 2003, pp. 137-151.

[14] M. Meloun, T. Syrový and A. Vrána, "The Thermodynamic Dissociation Constants of Ambroxol, Antazoline, Naphazoline, Oxymetazoline and Ranitidine by the Regression Analysis of Spectrophotometric Data," Talanta, Vol. 62, No. 3, 2004, pp. 511-522.

[15] M. Meloun, T. Syrový and A. Vrána, "The Thermodynamic Dissociation Constants of Losartan, Paracetamol, Phenylephrine and Quinine by the Regression Analysis of Spectrophotometric Data," Analytica Chimica Acta, Vol. 533, No. 1, 2005, pp. 97-110.

[16] M. Meloun, T. Syrový and A. Vrána, "The Thermodynamic Dissociation Constants of Haemanthamine, Lisuride, Metergoline and Nicergoline by the Regression Analysis of Spectrophotometric Data, Analytica Chimica Acta, Vol. 543, No. 1-2, 2005, pp. 254-266.

[17] M. Meloun, M. Javůrek and J. Militký, “Computer Estimation of Dissociation Constants. Part V: Regression Analysis of Extended Debye-Hückel Law," Microchimica Acta, Vol. 109, No. 2-3, 1992, pp. 221-231.

[18] M. Meloun, J. Havel and E. Högfeldt, "Computation of Solution Equilibria," Ellis Horwood, Chichester, 1988.

[19] M. Meloun and J. Havel, "Computation of Solution equilibria, Part 1: Spectrophotometry," Folia Facultatis Scientarum Naturalium Universitatis Purkynianae, Brno 1984.

[20] M. Meloun and J. Havel, "Computation of Solution equilibria, Part 2: Potentiometry," Folia Facultatis Scientarum Naturalium Universitatis Purkynianae, Brno 1985.

[21] M. Meloun, S. Bordovská, T. Syrový and A. Vrána, “Tutorial on Chemical Model Building and Testing to Spectroscopic Data with Least-Squares Regression," Analytica Chimica Acta, Vol. 580, No. 1, 2006, pp. 107-121.

[22] M. Meloun, S. Bordovská and T. Syrový, "A Novel 
Computational Strategy for the $\mathrm{pK}_{\mathrm{a}}$ Estimation of Drugs by Nonlinear Regression of Multiwavelength Spectrophotometric pH-Titration Data Exhibiting Small Changes," Journal of Physical Organic Chemistry, Vol. 20, 2007, pp. 690-701.

[23] M. Meloun, S. Bordovská and L. Galla, "The Thermodynamic Dissociation Constants of Four Non-Steroidal Anti-Inflammatory Drugs by the Least-Squares Nonlinear Regression of Multiwavelength Spectrophotometric $\mathrm{pH}-$ Titration Data," Journal of the Pharmaceutical and Biomedical Analysis, Vol. 45, No. 4, 2007, pp. 552-564.

[24] M. Meloun, S. Bordovská, Benchmarking and Validating Algorithms that Estimate $\mathrm{pK}_{\mathrm{a}}$ Values of Drugs Based on their Molecular Structures," Analytical and Bioanalytical Chemistry, Vol. 389, No. 4, 2007, pp. 1267-1281.

[25] M. Meloun, S. Bordovská and A. Vrána, "The Thermodynamic Dissociation Constants of the Anticancer Drugs Camptothecine, 7-Ethyl-10-Hydroxycamptothecine, 10Hydroxycamptothecine, and 7-Ethylcamptothecine by the Least-Squares Nonlinear Regression of Multiwavelength Spectrophotometric pH-Titration Data, Analytica Chimica Acta, Vol. 584, No. 2, 2007, pp. 419-432.

[26] M. Meloun, T. Syrový, S. Bordovská and A. Vrána, Reliability and Uncertainty in the Estimation of $\mathrm{pK}_{\mathrm{a}}$ by the Least Squares Nonlinear Regression Analysis of Multiwavelength Spectrophotometric $\mathrm{pH}$ Titration Data," Analytical and Bioanalytical Chemistry, Vol. 387, No. 3, 2007, pp. 941-955.

[27] L. G. Sillén and B. Warnqvist, "Equilibrium Constants and Model Testing from Spectrophotometric Data, Using LETAGROP," Acta Chemica Scandinavia, Vol. 22, 1968, pp. 3032-3034.

[28] D. J. Leggett, "Computational Methods for the Determination of Formation Constants," In: D. J. Leggett, Ed., Plenum Press, New York, 1985.

[29] J. Havel and M. Meloun, "Computational Methods for the Determination of Formation Constants," In: D. J. Leggett, Ed., Plenum Press, New York, 1985.

[30] M. Meloun, M. Javůrek and J. Havel, "Multiparametric curve Fitting-X. A Structural Classification of Program for Analysing Multicomponent Spectra and their Use in Equilibrium-Model Determination," Talanta, Vol. 33, No. 6, 1986, pp. 513-524.

[31] D. J. Leggett and W. A. E. McBryde, "General Computer Program for the Computation of Stability Constants from Absorbance Data," Analytical Chemistry, Vol. 47, No. 7, 1975, pp. 1065-1070.

[32] D. J. Leggett, "Numerical Analysis of Multicomponent Spectra," Analytical Chemistry, Vol. 49, No. 2, 1977, pp. 276- 281

[33] D. J. Leggett, S. L. Kelly, L. R. Shiue, Y. T. Wu, D. Chang and K. M. Kadish, "A Computational Approach to the Spectrophotometric Determination of Stability Constants-2: Application to Metalloporphyrin Axial Ligand Interactions in Non-Aqueous Solvents," Talanta, Vol. 30, No. 8, 1983, pp. 579-586.
[34] J. J. Kankare, "Computation of Equilibrium Constants for Multicomponent Systems from Spectrophoto-Metric Data," Analytical Chemistry, Vol. 42, No. 12, 1970, pp. 1322-1326.

[35] P. Gans, A. Sabatini and A. Vacca, "Investigation of Equilibria in Solution. Determination of Equilibrium Constants with the HYPERQUAD Suite of Programs," Talanta, Vol. 43, No. 10, 1996, pp. 1739-1753.

[36] H. Gampp, M. Maeder, C. J. Mayer and A. Zuberbuhler, "Calculation of Equilibrium Constants from Multiwavelength Spectroscopic Data-I: Mathematical Considerations, Talanta, Vol. 32, No. 2, 1985, pp. 95-101.

[37] H. Gampp., M. Maeder, C. J. Meyer and A. Zuberbühler, Calculation of Equilibrium Constants from Multiwavelength Spectroscopic Data-II: Specfit: Two User-Friendly Programs in Basic and Standard Fortran 77," Talanta, Vol. 32, No. 4, 1985, pp. 251-264.

[38] H. Gampp., M. Maeder, C. J. Meyer and A. Zuberbühler, "Calculation of Equilibrium Constants from Multiwavelength Spectroscopic Data-III: Model-Free Analysis of Spectrophotometric and ESR Titrations," Talanta, Vol. 32, No. 12, 1985, pp. 1133-1139.

[39] H. Gampp., M. Maeder, C. J. Meyer and A. Zuberbühler, "Calculation of Equilibrium Constants from Multiwavelength Spectroscopic Data-IV: Model-Free Least-Squares Refinement by Use of Evolving Factor Analysis, Talanta, Vol. 33, No. 12, 1986, pp. 943-951.

[40] K. Y. Tam and K. Takács-Novák, "Multi-Wavelength Spectrophotometric Determination of Acid Dissociation Constants: A Validation Study," Analytica Chimica Acta, Vol. 434, No. 1, 2001, pp. 157-167.

[41] SPECFIT/32, Spectrum Software Associates, Marlborough, 2004. http://www.bio-logic.info/rapid-kinetics/specfit. html

[42] T. H. Scheuermann, C. Keeler and M. E. Hodson, "Consequences of Binding an S-Adenosylmethionine Analogue on the Structure and Dynamics of the Thiopurine Methyltransferase Protein Backbone, Biochemistry, Vol. 43, No. 38, 2004, pp. 12198-12209.

[43] Pallas. http://compudrug.com/show.php?id=90. http:// compudrug.com/show.php?id=36.

[44] M. Meloun, J. Militký and M. Forina, Chemometrics for Analytical Chemistry-Vol. 1. PC-Aided Statistical Data Analysis, Ellis Horwood, Chichester, 1992.

[45] M. Meloun, J. Militký and M. Forina, Chemometrics for Analytical Chemistry-Vol. 2. PC-Aided Regression and Related Methods, Ellis Horwood, Chichester, 1994.

[46] ORIGIN, OriginLab Corporation, Northampton.

[47] M. Meloun, T. Syrový and A. Vrána, "Determination of the Number of Light-Absorbing Species in the Protonation Equilibria of Selected Drugs," Analytica Chimica Acta, Vol. 489, No. 2, 2003, pp. 137-151.

[48] S-PLUS. http://www.insightful.com/products/splus

[49] ADSTAT, ADSTAT 1.25, 2.0, 3.0 (Windows 95), TriloByte Statistical Software Ltd., Pardubice. 